\title{
A new approach to heterogeneity analysis in a highly complex carbonate reservoir by using borehole image and conventional log data
}

\author{
Mehdi Tadayoni $^{1} \cdot$ Mahmoudreza Khalilbeyg $^{2} \cdot$ Radzuan Bin Junin $^{1}$
}

Received: 5 January 2020 / Accepted: 8 June 2020 / Published online: 16 June 2020

(c) The Author(s) 2020

\begin{abstract}
This study outstretches a new method to specify the heterogeneity of the studied reservoir by combining BHI (Borehole Image $\log$ ) and conventional log data for 4 existing wells. The first step to achieve this goal was utilizing borehole electrical images to assess the quantity of vugs/modals fraction and porosity distribution. Spectrum porosity was calculated through probabilistic analysis based on core and FMI data which has specified two general types of porosity in studied field as primary porosity (microporosities and intercrystalline) and secondary porosity (vugs). Due to irregular dispersion, noncategorization, and scattering of the porosity-permeability graph obtained from laboratory core data, next step was using petrophysical image facies prediction for generating an electrical facies to incorporate the different reservoir quality. This lithology (litho types) is produced by BHI analysis which reflects geological and petrophysical properties of the field. Then a porosity-permeability cross-plot has been made based on core data and produced facies codes which build in the previous step to check the validity of BHI Facies code extraction. Finally, heterogeneity analysis has been done through an innovative step-by-step workflow to determine spectrum porosity log which is divided into 6 categories/portions as Resistive, Matrix, Isolated, Connected, Bed boundaries and Fractures porosity.
\end{abstract}

Keywords Image $\log \cdot$ Heterogeneity analysis $\cdot$ Borehole image $\cdot$ Facies codes $\cdot$ Carbonate reservoir

\section{Introduction}

Most of the literature on reservoir characterization and petrophysics refers to reservoirs as being heterogeneous in nature. However, reservoir characterization researchers

Electronic supplementary material The online version of this article (https://doi.org/10.1007/s13202-020-00930-4) contains supplementary material, which is available to authorized users.

Mehdi Tadayoni

mtadayoni@hoteng.com

Mahmoudreza Khalilbeyg

m.khalilbeyg@alumni.ut.ac.ir

Radzuan Bin Junin

r-radzuan@utm.my

1 Faculty of Petroleum and Renewable Energy Engineering, Universiti Teknologi Malaysia (UTM), Johor Bahru, Malaysia

2 School of Mining Engineering, College of Engineering, University of Tehran, Tehran, Iran are currently beginning to investigate the quantification of assorted heterogeneities, and the concept of heterogeneity as a scale-dependent descriptor (Frykman 2001; Jennings and Lucia 2003; Pranter et al. 2005; Westphal et al. 2004).

It is vital to fully comprehend the variability and distribution of petrophysical properties such as porosity and permeability throughout a reservoir. This is mainly correct in the case of carbonate reservoirs, which mostly have notable variability. Common reservoir heterogeneities include grain/rock component, grain size distribution, grain/rock distribution (mineralogy, fossils, and lithology), fluid distribution, pore system types, connectivity, sizes and cementation. These heterogeneities plainly affect petrophysical log responses (e.g. nuclear, resistivity and sonic) and derived petrophysical parameters such as porosity, saturation, and permeability (Fitch 2011).

Accurate awareness of the influence of heterogeneity on flow mechanisms is significant for expanding effective reservoir characterization and outline. However, the interplay of the physical processes of transport, through the complicated structures from the pore scale upward, isn't absolutely 
recognized (Bijeljic et al. 2013). Formation permeability that could be a key parameter for reservoir characterization controls the prescriptions related to well completion, stimulation, and reservoir management (Bagci and Akbas 2007; Potter 2007), and can affect reservoir performance (Sun et al. 2017).

The distinction between homogeneous and heterogeneous is often relative and is based on economic considerations (Nurmi et al. 1990). Heterogeneity is defined as the complexity and/or variability of the system property of interest in space, in terms of the ecological sciences ( $\mathrm{Li}$ and Reynolds 1995; Zhengquan et al. 1997). Within an ecological model, defined heterogeneity is variability in the density of discrete objects or entities in space. It is an inherent, ubiquitous and critical property that is strongly dependent on scales of observation and the methods of measurement used (Frazer et al. 2005).

In terms of dynamic responses, heterogeneity is defined as the dispersity of displacement front of the flooding process (Lake and Jensen 1989). Statically, heterogeneity is being described as the complexity of flow path and contrast of permeability. Within the geological framework, heterogeneity has multiple scales i.e. from core scale-well scale to reservoir scale. The reservoir usually consists of interbed heterogeneity and intrabed heterogeneity, which are modeled separately and have a different impact on dynamic responses (Tang and Liu 2008).

On a decimetre scale of examination, porosity is sometimes distributed homogeneously but is more commonly heterogeneous. In addition to vugs and fractures, there are four basic geometrical fabrics of decimetre-scale porosity. Layering is the most common, sometimes clearly associated with stratification. However, the thickness of porosity layers can be uniform or quite variable within the same formation. The next most common heterogeneous fabric is patchy porosity distribution. This fabric can either be patches of high porosity within low-porosity intervals or patches of low-porosity rock within porous reservoir zones. A common porosity fabric in Cretaceous and Tertiary carbonate shelf reservoirs is a three-dimensional convoluted continuous mixture of low- and high-porosity rock volumes. This porosity fabric is sometimes associated with isolated patches of either high- or low-porosity rock, although no obvious genetic transitions of these two fabrics have been observed in images, cores, or outcrops (Nurmi et al. 1990).

Dykstra-Parson coefficient $\left(\mathrm{Vd}_{\mathrm{p}}\right)$ and Lorenz coefficient $\left(\mathrm{L}_{\mathrm{c}}\right)$ are the two most used parameters for heterogeneity quantification. $\mathrm{Vd}_{\mathrm{p}}$ is computed by using quintiles of permeability log-normal distribution. Even though it is robust to log normally assumption and has mainly two disadvantages. One is the nonuniqueness of it; multiple static models could have the same $\mathrm{Vd}_{\mathrm{p}}$, although, dynamically, they are different. Another disadvantage is a little subtle: $\mathrm{Vd}_{\mathrm{p}}$ has low sensitivity of models to variations in $\mathrm{Vd}_{\mathrm{p}}$ when $\mathrm{Vd}_{\mathrm{p}}<0.5$ and high sensitivity of models to variation when $\mathrm{Vd}_{\mathrm{p}}>0.5$. Schmalz introduced $\mathrm{L}_{\mathrm{c}}$, which is defined by the Lorenz plot, a cross-plot between flow capacities vs. storage capacity. The $\mathrm{L}_{\mathrm{c}}$ is computed from the area under the $\mathrm{L}_{\mathrm{c}}$ curve minus 0.5 . $\mathrm{L}_{\mathrm{c}}$ ranges from 0 to 1 (homogenous to heterogeneous). Similar to $\mathrm{Vd}_{\mathrm{p}}, \mathrm{L}_{\mathrm{c}}$ is not a unique parameter for characterization of reservoir heterogeneity. $\mathrm{L}_{\mathrm{c}}$ is better than $\mathrm{Vdp}$ because it includes porosity or storage capacity and weight (Fitch 2011).

In this study, heterogeneity analysis will be done as a new approach for a highly complex carbonate reservoir with an innovative step-by-step workflow which will be discussed.

\section{Porosity spectrum determination}

Most carbonate formation evaluation methods are connected to data analysis using traditional resistivity and porosity logs. For many carbonate reservoirs, the correlation between the production of hydrocarbons and a density-neutron log is inconsistent. Good production is a time interval in which logs have low porosity, while areas with higher porosity are not produced. Production of total carbonate reservoirs in adult fields is often more than expected from the standard porosity profile.

Many productive carbonates have advanced dual porosity systems with wide variable proportions of primary and secondary porosities. The secondary porosity might contain fractures, modals (unimodal or bimodal), vugs, and channels. Therewith, the originally homogeneous matrix/intergranular primary porosity might become patchy through selective cementation of the matrix. On the traditional porosity logs, these porosity sorts typically seem somewhat uniformly distributed. Moreover, because of the coarse resolution of standard tools, such styles of porosity get under-estimated or unmarked.

Borehole electrical images, FMI in particular, provide both high resolution and azimuthal borehole coverage to resolve quantitatively the heterogeneous nature of porosity components. This approach has been introduced as a new method to utilize borehole electrical images in the analysis of carbonate reservoir porosity system (Akbar et al. 2000; Newberry et al. 1996). Through this technique, the porosity distribution and quantity of vugs/modals fraction can be obtained. However, the results of the technique are affected largely by shale and bad-hole conditions. In case the quality of one or two images is largely affected due to damaged FMI pad or bad hole, such images can be discarded during the analysis.

The basic assumption for this technique is that the resistivity data from the electrical images is measured in the flushed zone of the borehole. Then, the electrical images 
after their calibration are converted to the porosity of the porosity map with shallow resistivity and porosity of the input (preferably effective porosity). Equation (1) is used for such developments; it takes log porosity (effective log porosity being the best option), any shallow resistivity measurement (mostly LLS or SFLU), and conductivity of individual FMI electrodes/buttons $\left(C_{\mathrm{i}}\right)$ as inputs.

$(\Phi)_{\mathrm{FMI} * / \mathrm{FMS}}=(\Phi)_{\log } *\left[\mathrm{LLS} * C_{i}\right]^{1 / m}$

Below the porosity threshold correspond to the host pores and the one above correspond to macro-secondary. There are three different types of thresholds/cut-offs that are applied to the porosity data. The description of each method is given in Table 1.

Throughout the homogeneous carbonate intervals, which compute unimodal porosity distribution, the average porosity of the image is approximately equal to the effective log porosity. Distribution of unimodal porosity over the heterogeneous carbonate intervals turns into a bimodal, trimodal or broad distribution. The average porosity of the image in these intervals can be more or less than the effective log porosity, depending on the heterogeneity, i.e., dense regions, vugs, modals, matrix patches of very high porosity, dense streaks or high porosity streaks. Figure 1 shows the porosity spectrum in well \#2 with analytical analysis and above cutoffs in all formations which shows high porosity formations as Mauddud-Z2 (MD-Z2) and Upper Shuaiba-Z1 (USH-Z1).

\section{Porosity classification}

The spectrum porosity in this field was calculated through probabilistic analysis using full set logs available in all wells. The amount of uncertainty is raised where the quality of the $\log$ is poor due to hole condition. Fortunately, fair certainty exists in the main reservoirs in which core porosity and interpreted log porosity are in good agreement. The porosity should be used with consideration where the log has not been acquired with reasonable reading, especially in vugs/ modals hole and washed out intervals. Based on core and FMI data two general types of porosity primarily and secondary are recognized which are including micro-porosity or inter-crystalline and vug porosity. FMI texture analysis shows a different type of porosity. The micro- and macroporosity can be interpreted based on Image log analysis.

Figure 2 mostly shows the distribution of one secondary porosity (vug) in the upper section in Mauddud, U. Shuaiba and L. Shuaiba Formation in interval without any types of fractures. Figure 3 indicates the distribution of two kinds of porosity; matrix (intergranular) and vug porosity as the second porosity in the Middle and lower section of all reservoir intervals. All of these signs show complex heterogeneity in studied reservoir field.

\section{Litho facies assessment}

Accessible research facility information for four wells was examined to acquire porosity and permeability of the considered reservoir. The aftereffects of these tests appear in the accompanying semi-logarithm graph (Fig. 4). As appeared in this figure, other than the general conveyance of this information, no assessment is feasible, and their scattering, nonclassification, and widespread distribution can't reflect geological and petrophysical properties straightforwardly and influencing production stage. To fathom this issue, another technique is proposed utilizing the Borehole Image Log investigation to produce an electrical facies that are talked about beneath.

\section{Petrophysical facies prediction}

Due to the heterogeneity of formation permeability shown in Fig. 4, it is necessary to have a qualitative type of classification to increase the accuracy of the information and achieving more realistic values of geological and petrophysical properties. This will be done through image facies prediction

Table 1 Three applied methods for porosity analysis

\begin{tabular}{ll}
\hline Method & Description \\
\hline WN threshold method & $\begin{array}{c}\text { First, the standard deviation of the histogram below the median porosity is computed. Then the cutoff/threshold } \\
\text { is obtained by adding a multiple of this standard deviation to the median porosity }\end{array}$ \\
$\begin{array}{l}\text { This is a variant of WN method. It locates the threshold at a fixed percentage. The percentage value is not fixed } \\
\text { and It may be greater or smaller than a certain value. Core observation/measurement provides a way to fix its } \\
\text { value }\end{array}$ \\
$\begin{array}{l}\text { It involves the use of discriminant threshold selection algorithm, which is based on the standard linear discrimi- } \\
\text { nant analysis used in the field of pattern recognition and statistics. This method works on the idea that if the } \\
\text { porosity data consists of two populations, then the best threshold should maximally separate the two means. } \\
\text { Average of the overall porosity seen collectively by all buttons/electrodes are also computed }\end{array}$ \\
\hline
\end{tabular}


Fig. 1 Porosity Spectrum in well \#2. Track 5: Porosity spectrum, Track 6 : vug porosity by WN method, Track 7: Vug porosity by SDR method, Track 8: Vug porosity by TSR method, Track 9: Final vug porosity

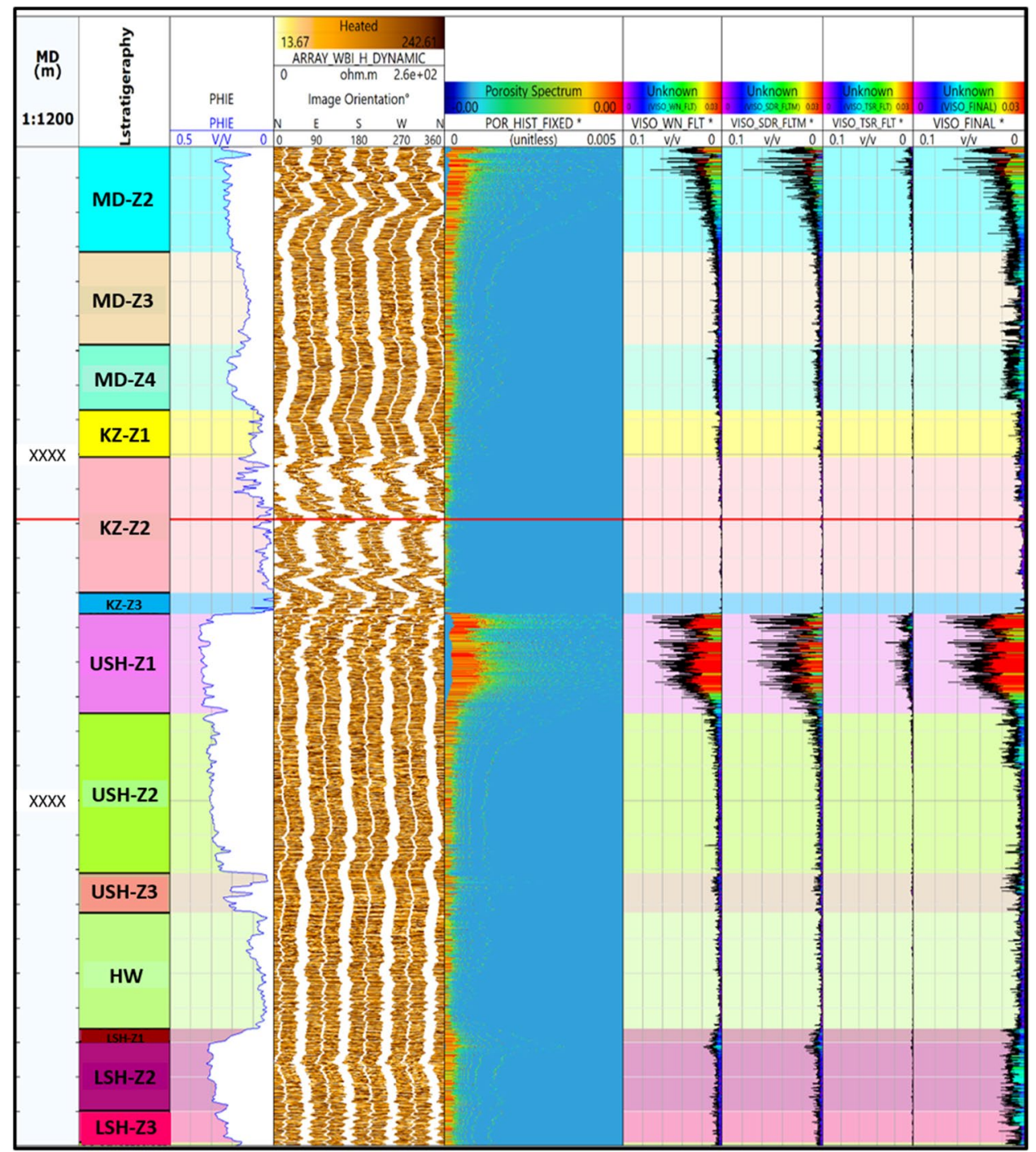

stage. The aim of the image facies prediction is to generate an electrical facies to incorporate the different reservoir quality using the different lithology (or lithotypes) produced from the BHI (Borehole Image Log) analysis which reflects geological and petrophysical properties. Because of scattering from the image appearance, different facies can be recognized as a very conductive zone (good reservoir characterization: usually in carbonate intervals, conductive zone as a dark section contains high porosity and permeability as a good path for fluid immigration), conductive zone (Moderate reservoir characterization), weak zone and tight intervals. This curve shows the tight carbonate (cemented grainstone or packstone) in a grey color, light and dark blue (seeming wackestone to packstone) as a moderate reservoir characterization, the greenish and orange one represents the good potential (packstone to grainstone).

Facies (or litho-types) analysis by image log uses a threshold to bin array or ordinary variables into up to 10 bins and classifies the data according to the relative abundance of each bin. In this filed resistivity or conductivity images can be threshold into 5 classes as described above. The red section in Fig. 5 shows highly vuggy intervals in the Upper part of Mauddud Formation.

Frequency of these color spectrums is shown in Fig. 6. Based on this figure, a comparison between facies map in Fig. 5 and CMR T2 distribution, prove the litho-types in different facies. Obviously, there is a reduction in reservoir quality from orange to light blue color. 

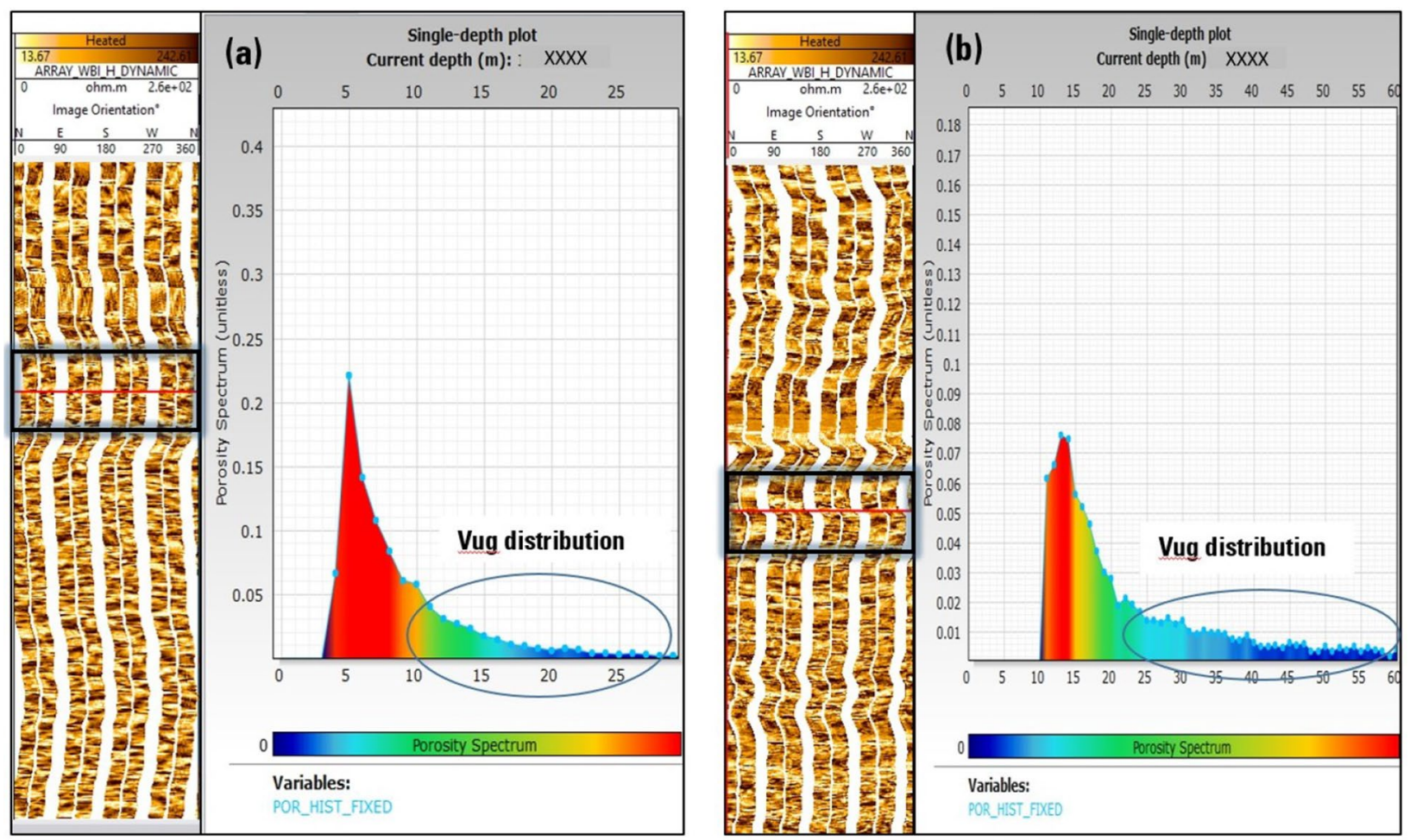

Fig. 2 Distribution of porosity type. Shows mostly secondary type of porosity (huge amount of vug) in a Mauddud Formation and b U. Shuaiba formation in well \#2
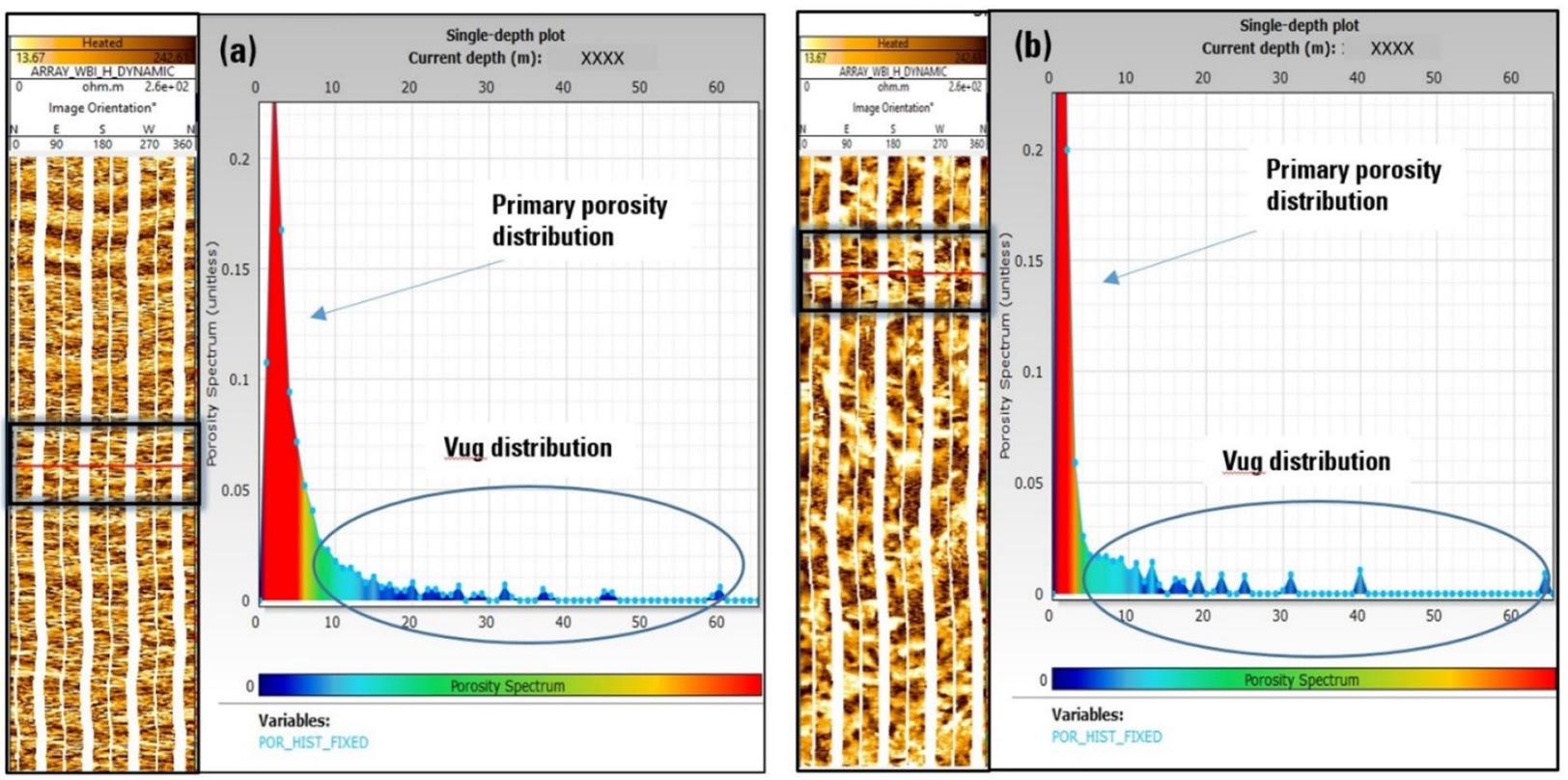

Fig. 3 Distribution of porosity type. Shows mostly secondary type of porosity in a U. Shuaiba Formation and b L. Shuaiba Formation in well \#2 
Fig. 4 Porosity Permeability transform in Mauddud and Shuaiba Formation for 4 wells. Note Irregular dispersion, noncategorization, and scattering of porosity-permeability data. There is no classification base on quality of data and the only classification is not acceptable for quality of the permeability

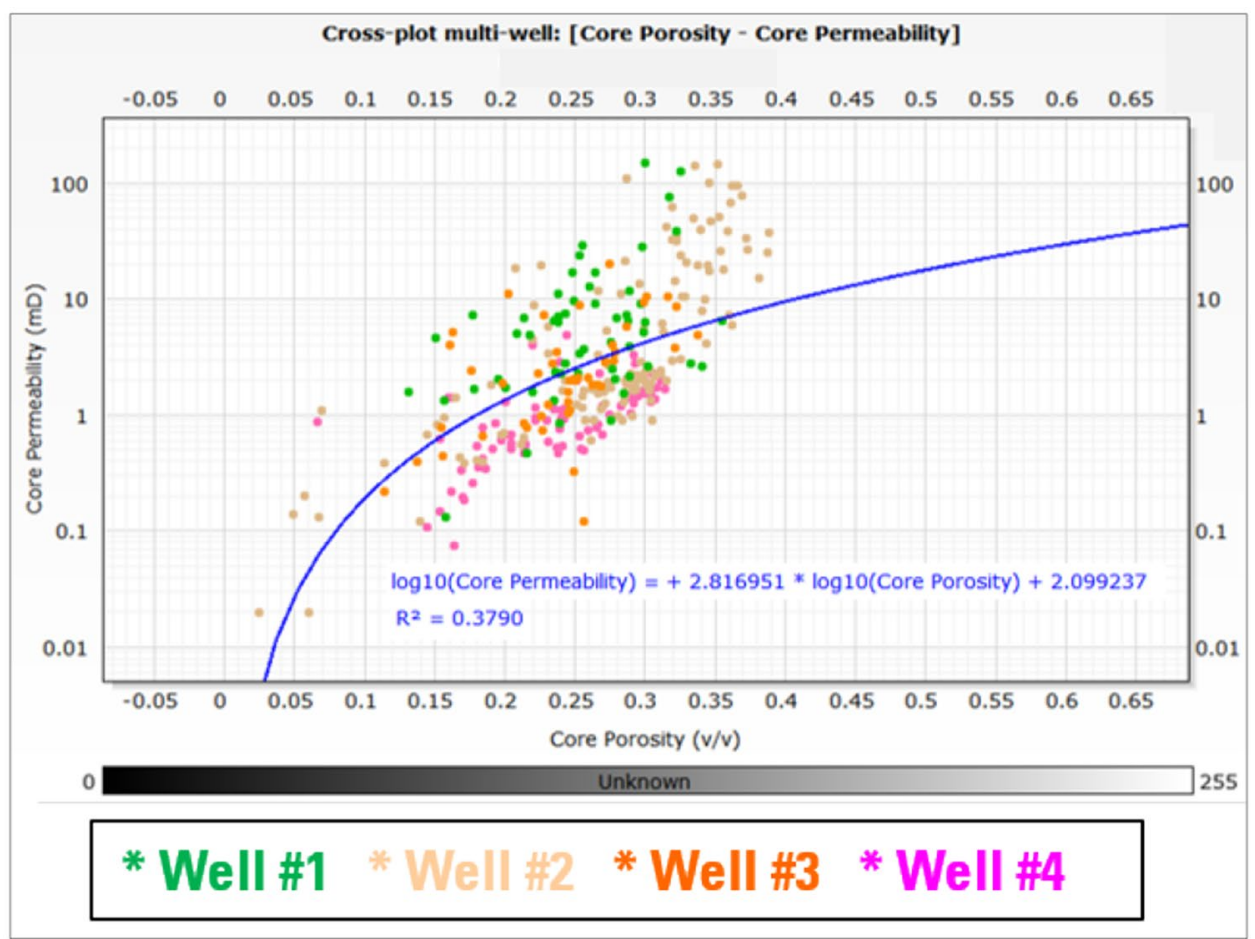

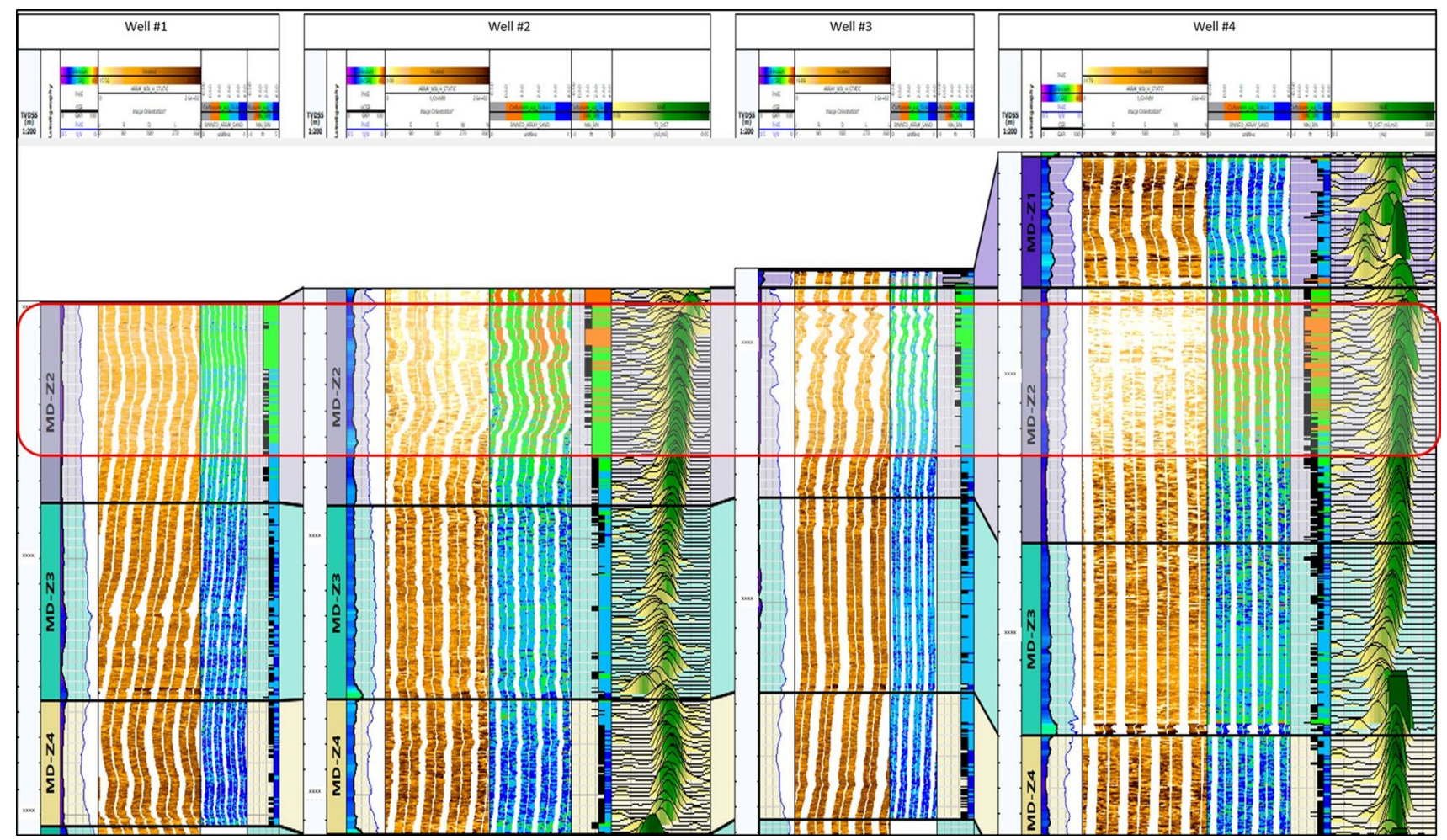

Fig. 5 Facies determination by FMI data in 4 wells in Mauddud Formation; Track 3: GR, Porosity. Track 4: Image Static, Track 5: Facies Image, Track 6: Facies Code. Track 7: T2 Distribution in 2 wells. Red section shows highly vuggy intervals in the Upper part of Mauddud Formation 

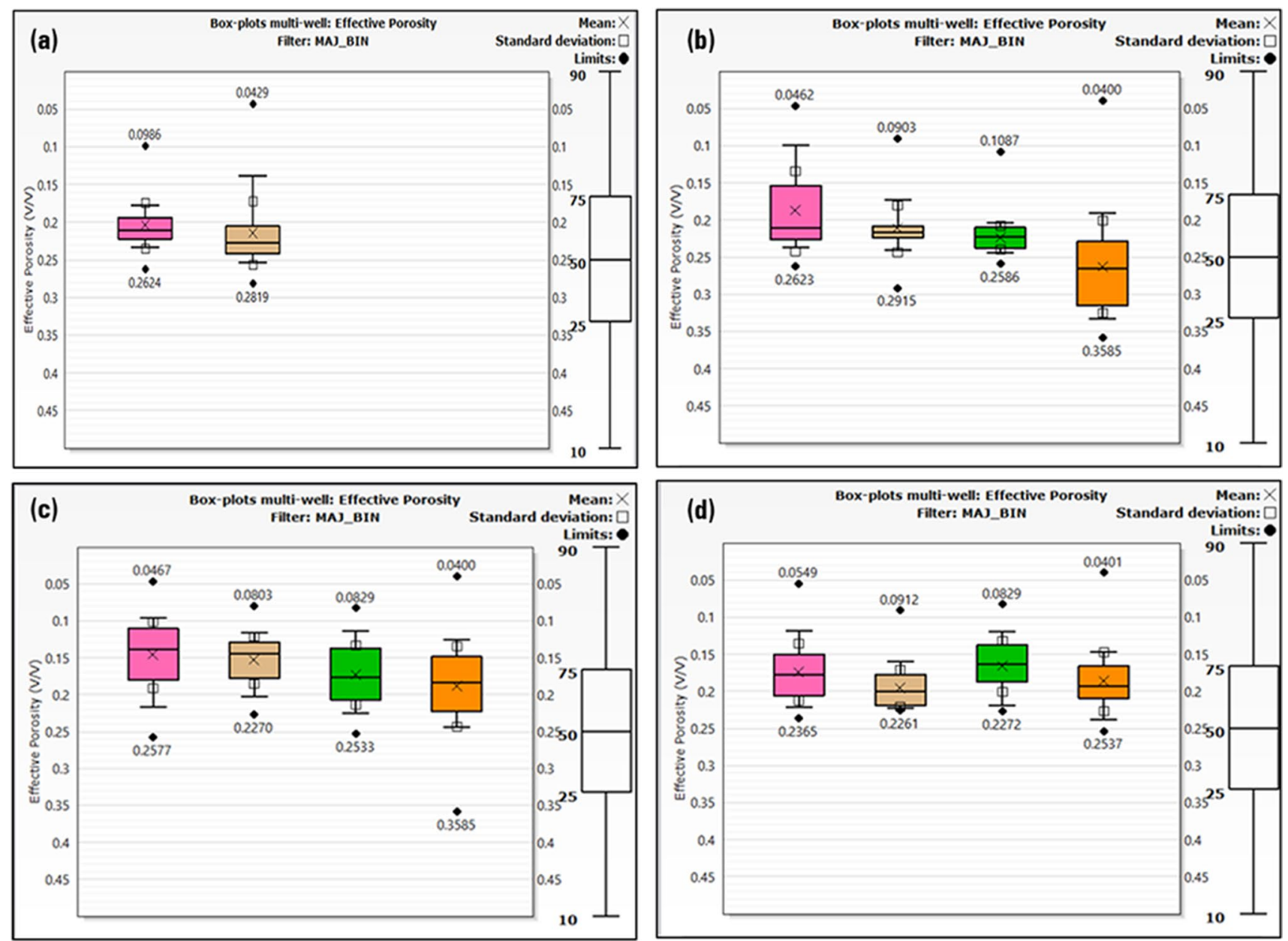

*Well \#1 * Well \#2 * Well \#3 * Well \#4

Fig. 6 Facies Codes frequencies in all Formations and for all studied wells. a Facies Code 1—Orange one in FMI, b Facies Code 2-Green one in FMI, $\mathbf{c}$ Facies Code 3-Light Blue in FMI and $\mathbf{d}$ Facies Code 4-Dark Blue in FMI

\section{Validation of facies code on conventional data}

After creating the electrical facies, the graph of permeability-porosity can be re-plotted using the newly introduced color filter and changed the type of bundle from well to well, to the electrical facies to verified new filtering approach. Accordingly, the porosity-permeability cross-plot is shown in Fig. 7 with respect to electrical facies as a colored filter. Drawing this data on facies codes made a chance to reduce uncertainty and based on Table 2 which shows porosity-functions, the consistency between facies codes and porosity-permeability core data are obvious. This is first validating for this new approach.
Another validating way is using RHOB-NPHI cross-plot with respect to facies analysis codes as dot colors. Figure 8 shows the distribution of different litho-types which were obtained by Image logs. Reservoir quality changing will be shown from orange one to light blue color separately in Mauddud and Shuaiba Formation. These values and their colors show validation for the litho-facies classification approach.

\section{Vertically and horizontally heterogeneity}

Based on analysis of existed advanced log data such as Sonic Scanner, FMI and CMR, it was obvious to see different types 

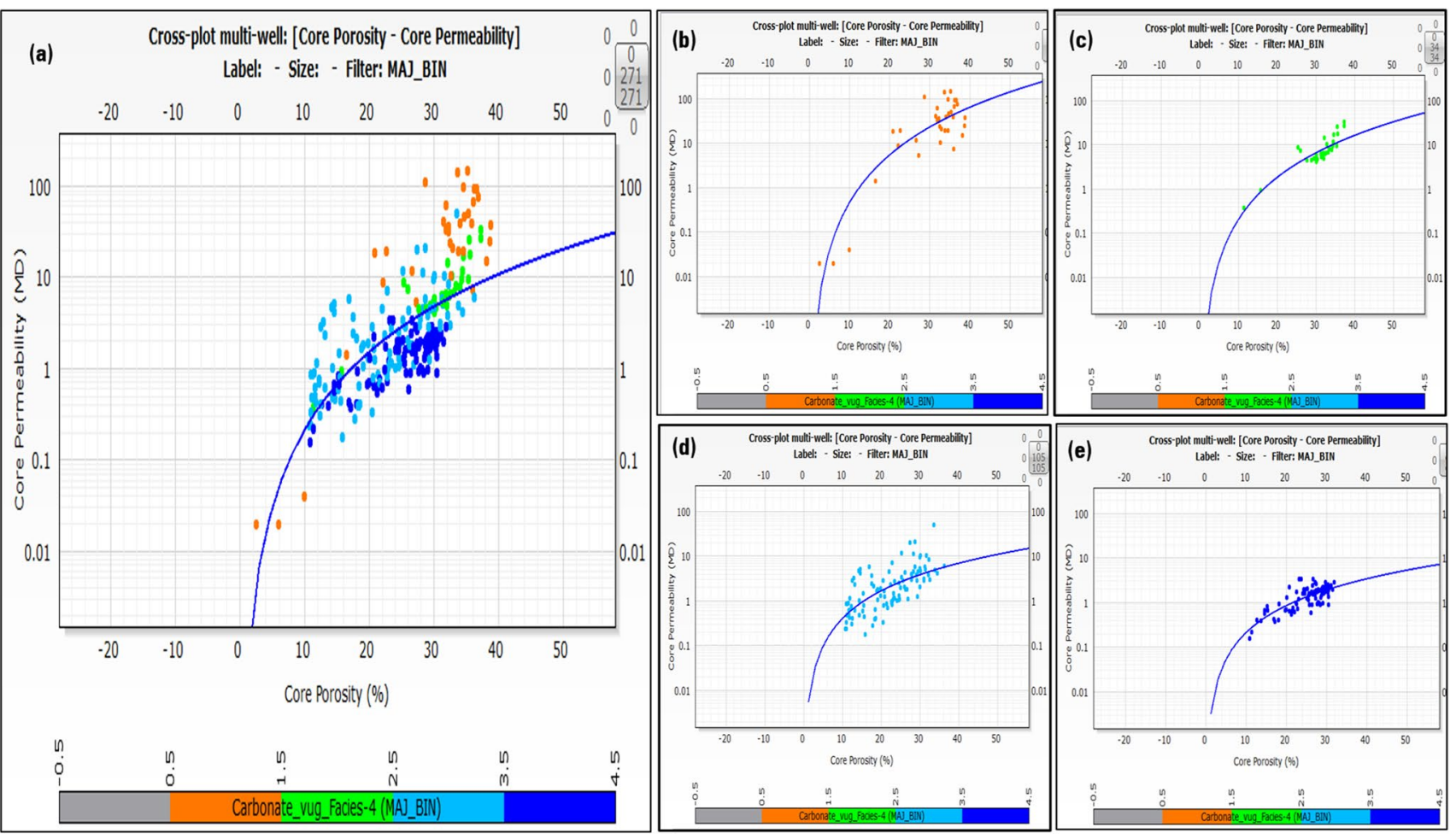

Fig. 7 Porosity Permeability transform in Mauddud and Shuaiba Formation. a all Facies Codes, b Facies Code 1, c Facies Code 2, d Facies Code 3 and e Facies Code 4

Table 2 Porosity-permeability function on Facies code in study fields

\begin{tabular}{llll}
\hline Facies code & Formation & Por-Perm function & $R^{2}$ \\
\hline 1 & Mauddud, Shuaiba & $\log (K$-core $)=3.5615 * \log ($ Por_core $)-3.892$ & 0.91 \\
2 & Mauddud, Shuaiba & $\log (K$-core $)=3.1536 * \log ($ Por_core $)-3.832$ & 0.86 \\
3 & Mauddud, Shuaiba & $\log (K$-core $)=2.1 * \log ($ Por_core $)-2.435$ & 0.65 \\
4 & Mauddud, Shuaiba & $\log (K$-core $)=2.0 * \log ($ Por_core $)-2.67$ & 0.79 \\
\hline
\end{tabular}
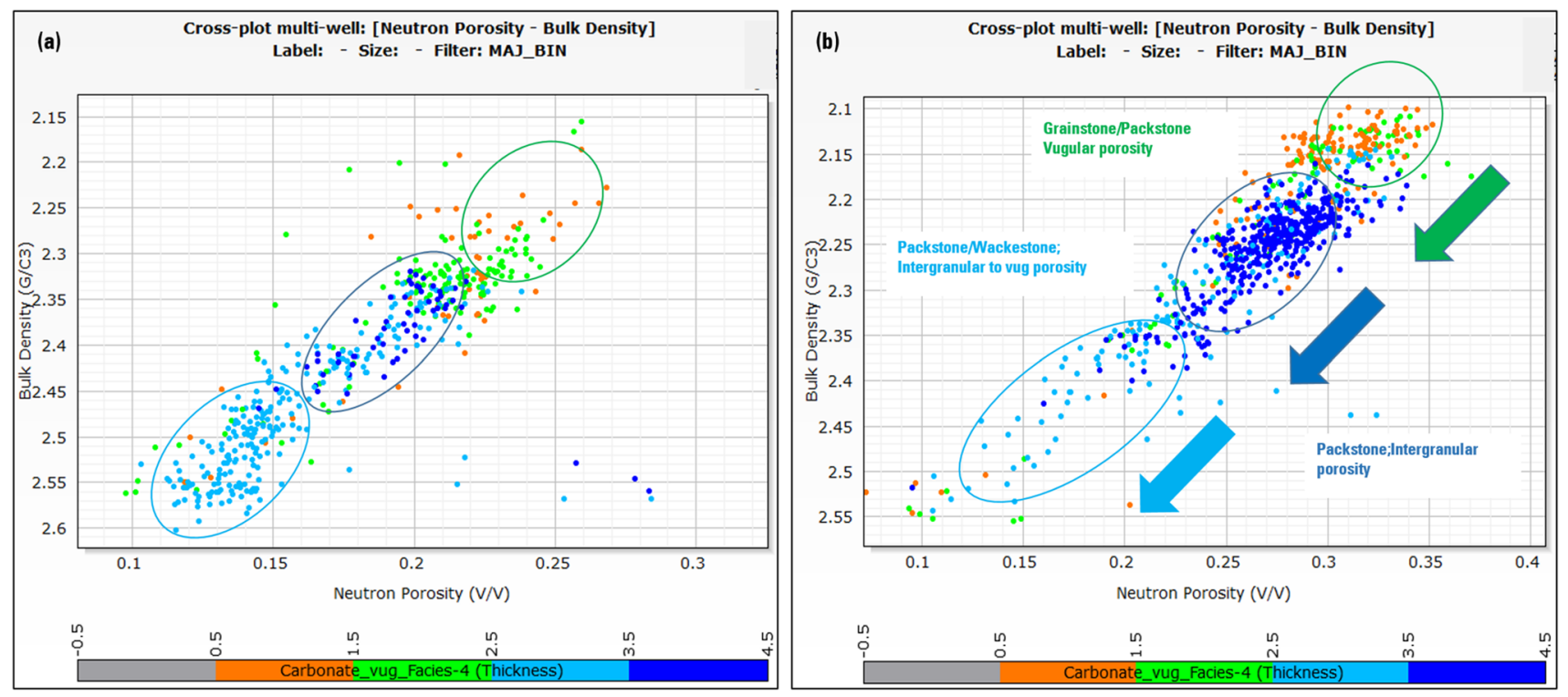

Fig. 8 NPHI-RHOB distribution in a Mauddud Formation and b Shuaiba Formation

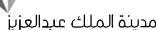

KACST مدئل 

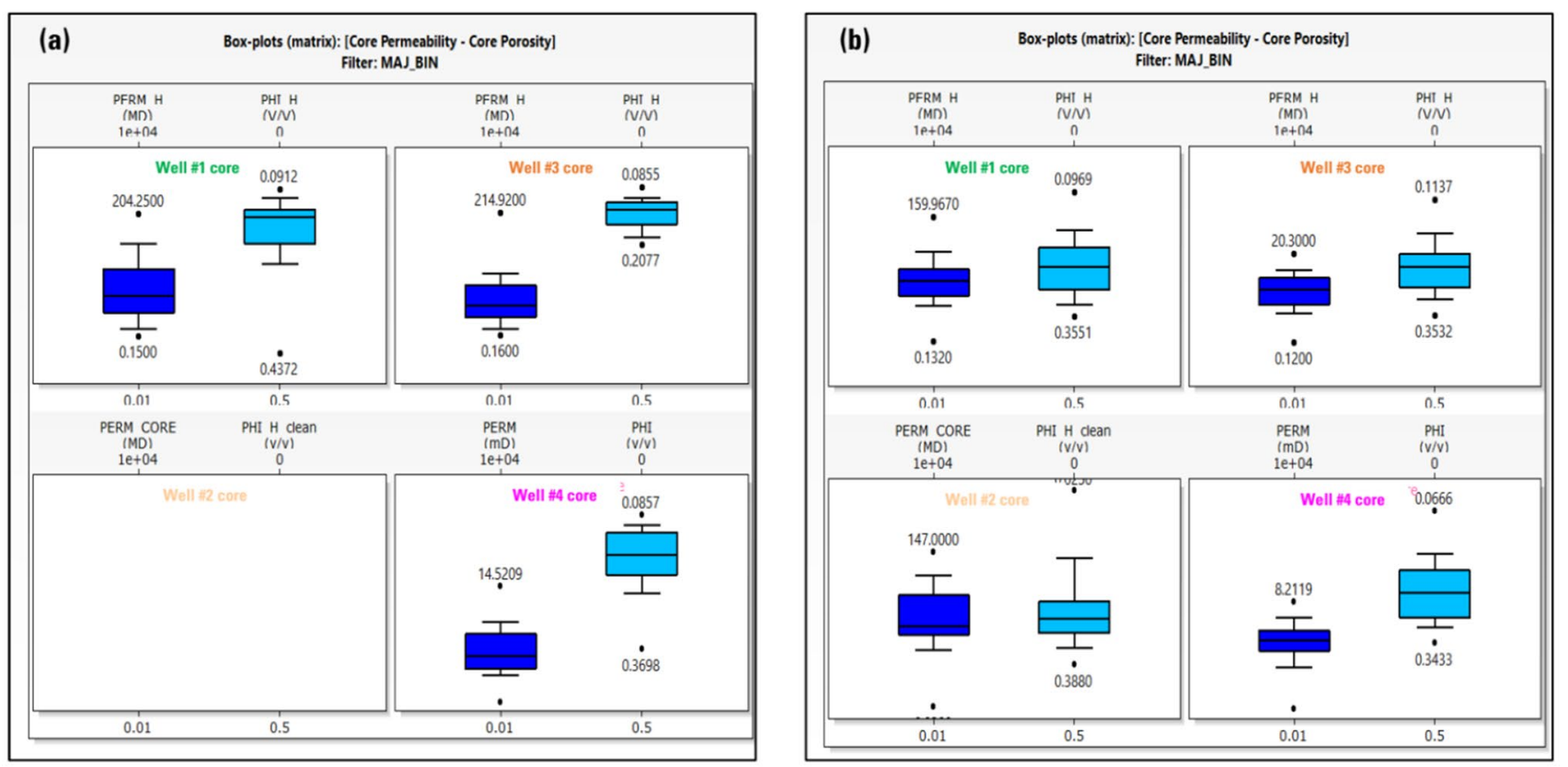

Fig. 9 Porosity-Permeability distribution box plot for cores data in a Mauddud and b Shuaiba Formations

and size of porosity. Figure 9 indicates the core porosity and permeability measurement in Mauddud and Shuaiba Formation in all 4 wells, and it shows that these formations are not homogeneous. Another indication for heterogeneity of this formation is low permeability value in comparison of high porosity. In porosity range from 30 to $40 \%$ (grainstone to packstone facies) permeability is about 30 to $100 \mathrm{mD}$ (Fig. 7a).

Distribution of vuggy porosity in all reservoir is another indicator for heterogeneity of Mauddud and Shuaiba Formation. Based on Image log evaluation, there is high vertical heterogeneity from Mauddud to L. Shuaiba Formations. Vuggy interval, Matrix, different layering, Barriers all are shown in Fig. 10. As shown in this figure, although based on the porosity track, different formations have high porosity, the lithofacies track shows that the connectivity of these porosities is different in terms of effective permeability. For instance, although the porosity in the Upper and Lower Shuaiba Formations (USH-Z1 and LSH-Z2) is close to each other, the permeability of the lower formation is much lower than its equivalent one in upper formation. This is a sign of vertical heterogeneity in studied field permeability.

No faults were observed according to available seismic investigation in this field. But due to the porosity distribution and porosity texture of 4 studied wells which are shown in
Fig. 11, there can be a horizontal heterogeneity in this field. This expression can be proved by variable texture and porosity distribution for well \#4 which illustrate the significant difference with other wells in a constant formation (Upper Shuaiba Formation). In the Upper section of L. Shuaiba Formation, the nature of reservoir totally is changed. Expect of vuggy interval, very low energy environment by horizontal layering is also illustrated. This section includes a series of high barriers and conductive intervals, also it is ended by sharp boundary and the vuggy intervals could be seen below of well bedded interval. All these phenomena show high heterogeneous reservoir that may affect all reservoir parameters such as Archie coefficients, water saturation models, porosity estimation, vertical and horizontal permeability, drilling of horizontal well and well trajectory.

\section{Heterogeneity analysis workflow}

Previous evaluations show a high level of heterogeneity and also lack of fracture (no fracture shown in image log in well \#2 Fig. 10) in the study field. For heterogeneity analysis, this study concentrates on a new approach which builds by an innovative step-by-step workflow (Fig. 12). Each step has a 


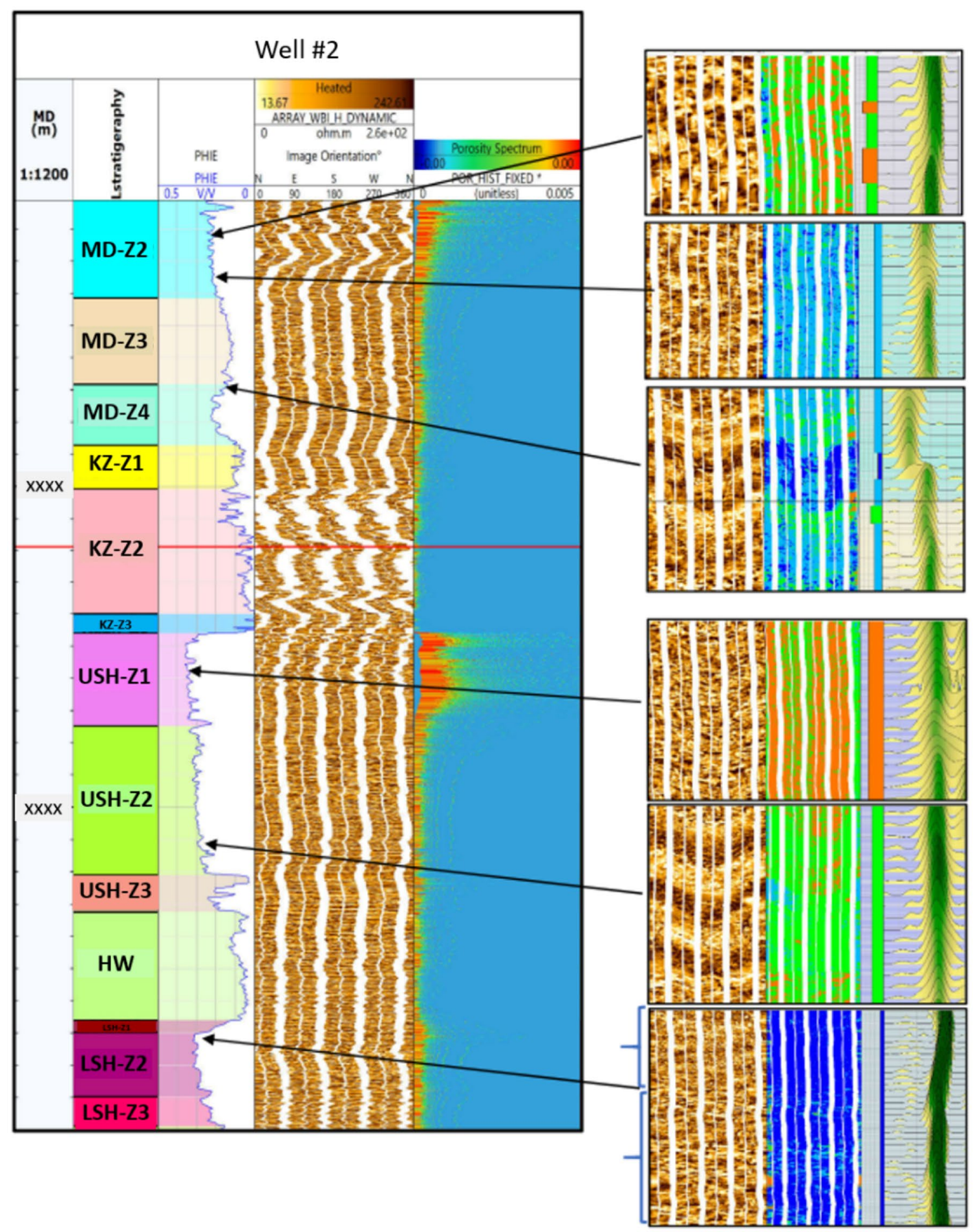

Fig. 10 Porosity distribution vertically from Mauddud to L. Shuaiba Formation in well \#2 


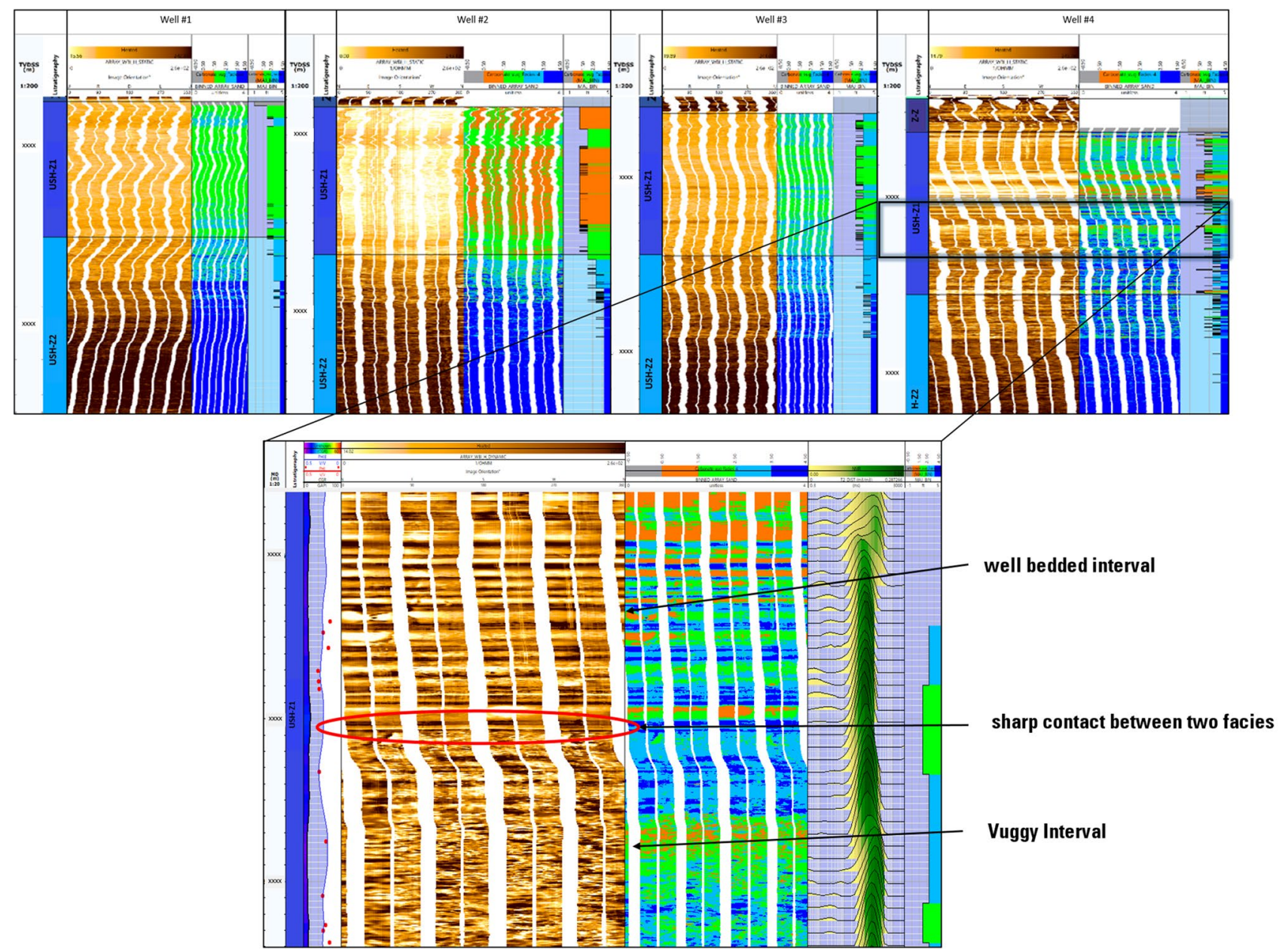

Fig. 11 Laterally heterogeneity in Upper Shuaiba Formation in well \#4. Although there is no textural change in the Upper Shuaiba Formation in wells 1 to 3, the Well \#4 indicates an obvious textural change in Upper Shuaiba Formation

unique description, processing, workflow, and output which are described in "Appendix" section of this study.

\section{Results and discussions}

In "Image Log Features Evaluation step" (Step 2), two different types of bed boundaries have been identified in well \#2. Structural bed boundaries (50 features) occur mainly in intervals where there are shale layers in contact with limy layers. The dip computed based on these structural bed boundaries is 4-5 degrees to S44W. There are also 204 non-structural bed boundaries, which are believed to be produced by diagenetic processes. These bed boundaries were not used to estimate structural dip due to the likely effect of diagenesis on their attitude.
This structural dip is consistent throughout the logged interval, and there is no indication of any major structural boundary, e.g., fault or angular unconformity. Fractures are very rare in this field. Only two fractures with a resistive trace and slight displacement in their plane have been detected in the interval. These have been classified as shear fractures. There are also five conductive fractures with a discontinuous trace identified in the interval, which is interpreted as open fissures. There are three intervals with high values of secondary porosity in Mauddud and Shuaiba Formations. These intervals are dominated by dissolution features, which are likely to have a strong influence on the permeability. Figure 13 shows these features.

In "Heterogeneity Delineation step" (step 6), size, value, contrast, and surface proportion of each heterogeneity are computed and represented as curves in Figs. 14, 15. 


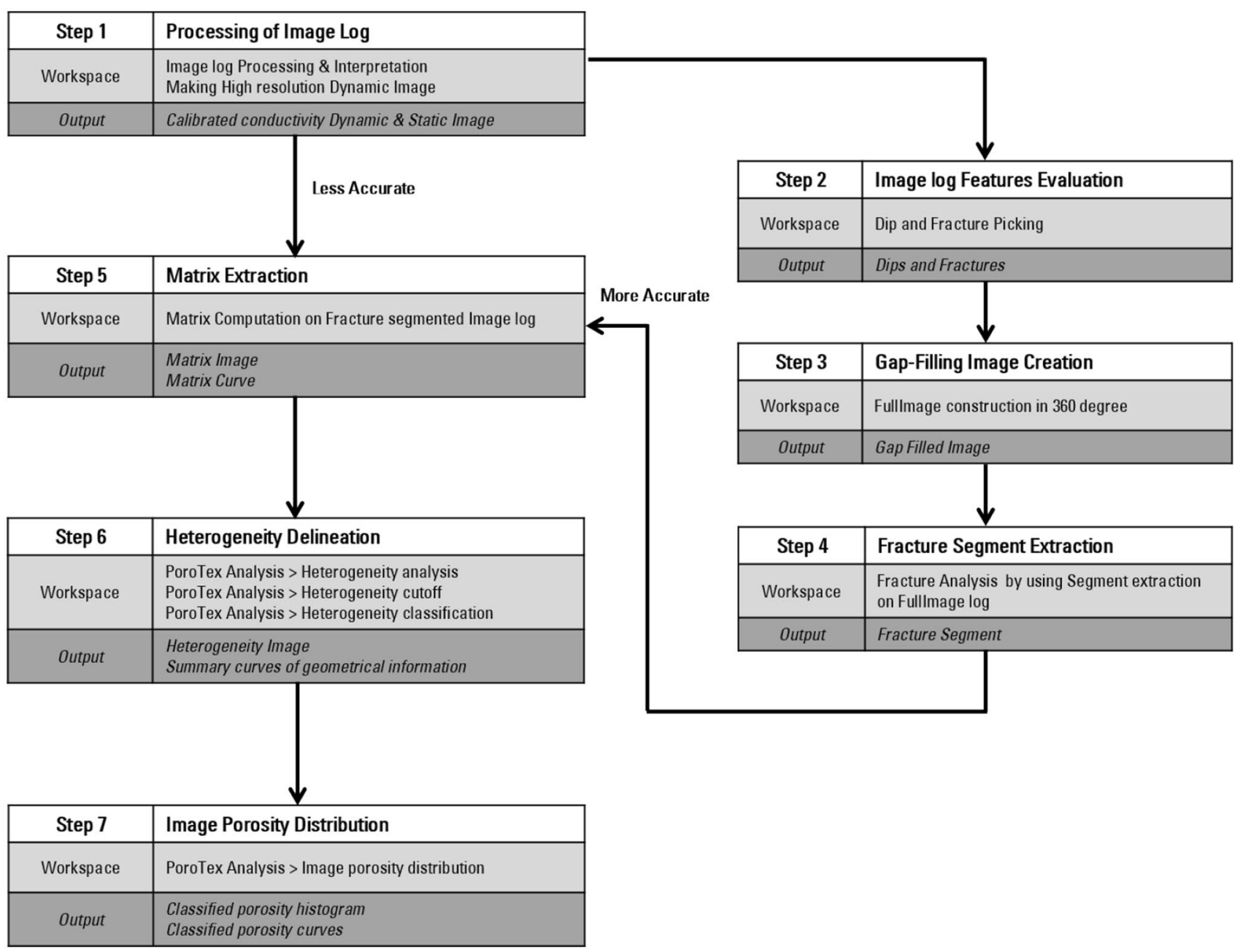

Fig. 12 Heterogeneity analysis workflow. Note that there are 3 optional steps which increase the accuracy of the analysis

Track 8 for Step 6 in Fig. 16 shows different heterogeneities in different colors. Based on the above discussion, primary and secondary porosities (vuggy porosity) are common in this field. Green and red color codes indicate the distribution of disconnected and connected vugs, respectively, in Mauddud and U. Shuaiba Formations (Track 4 in Fig. 17). The bend is characterized by the normal of the contrasts in conductivity between framework and peak line (zero in the event that there's no line) at each profundity level.

In "Image Porosity Distribution step" (step 7), in Fig. 18, Tracks 9 to 13 show share of different porosities such as resistive, connected, disconnected porosity value for well \#4. In this well, U. Shuaiba Formation contains more connected porosity (red color) and the share of Matrix porosity (primary porosity) and disconnected porosity increase in deeper intervals (step 7).

\section{Conclusions}

In carbonate reservoir, advanced log such as BHI data has a vital important role for heterogeneity analysis. Upper Shuaiba and Upper Mauddud Formations are the main intervals which have been exposing by meteoric water and based on image $\log$ in 4 wells these formations mostly contain bimodal and trimodal pores from matrix to vuggy porosity. All vuggy intervals were seen obviously on image log which are classified to connected and unconnected vuggs. So this kind of matrix with various pore types is indicator of heterogeneous media. In this environment normal approaches for formation evaluation do not work properly. Open hole logs (GR, NPHI, RHOB, DT, DLL) are not able to be utilized in reservoir characterization and only shows the trend of pore types changes. 
Fig. 13 Image log interpretation (bedding in green and fracture in blue one) in well \#2
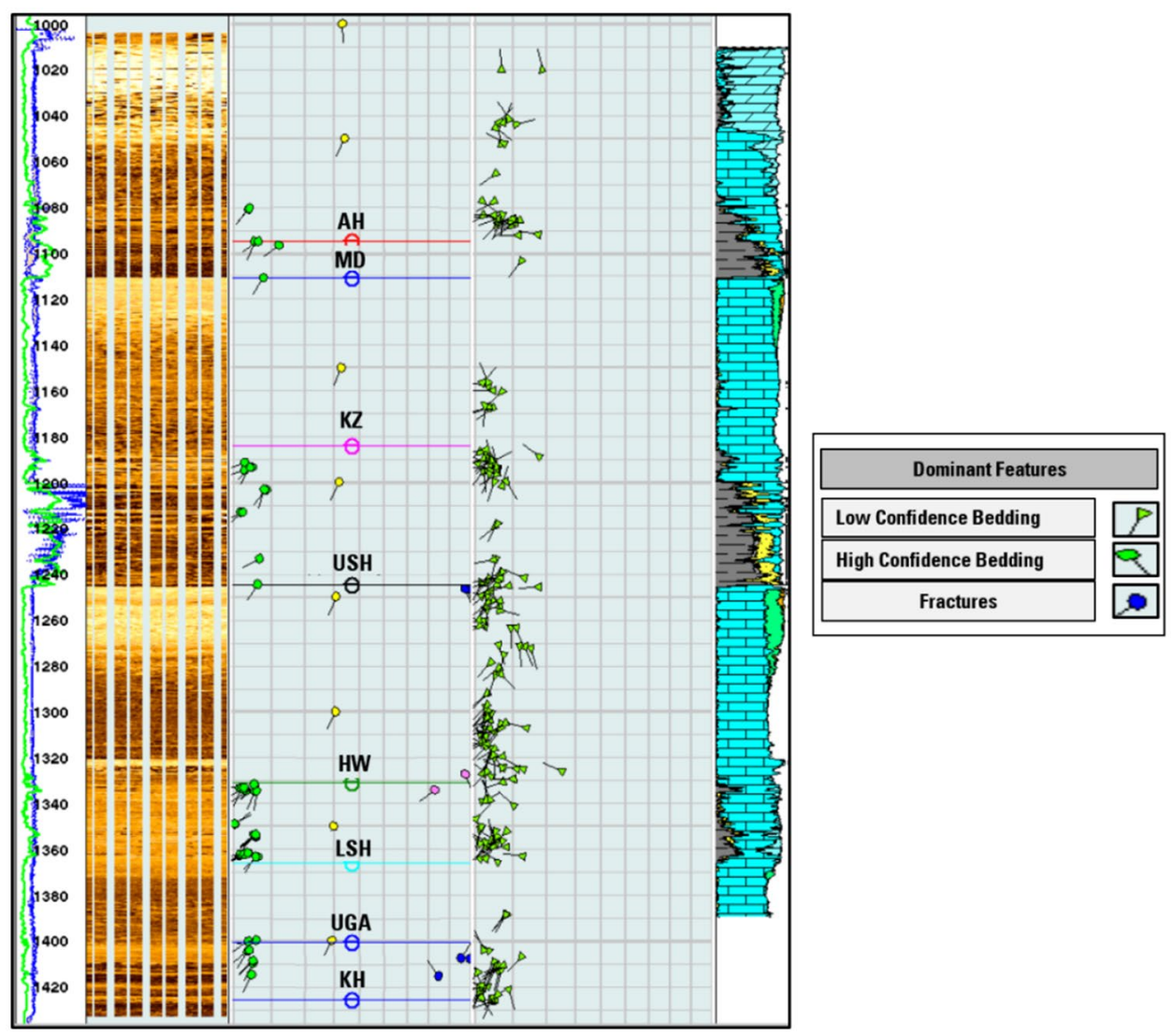
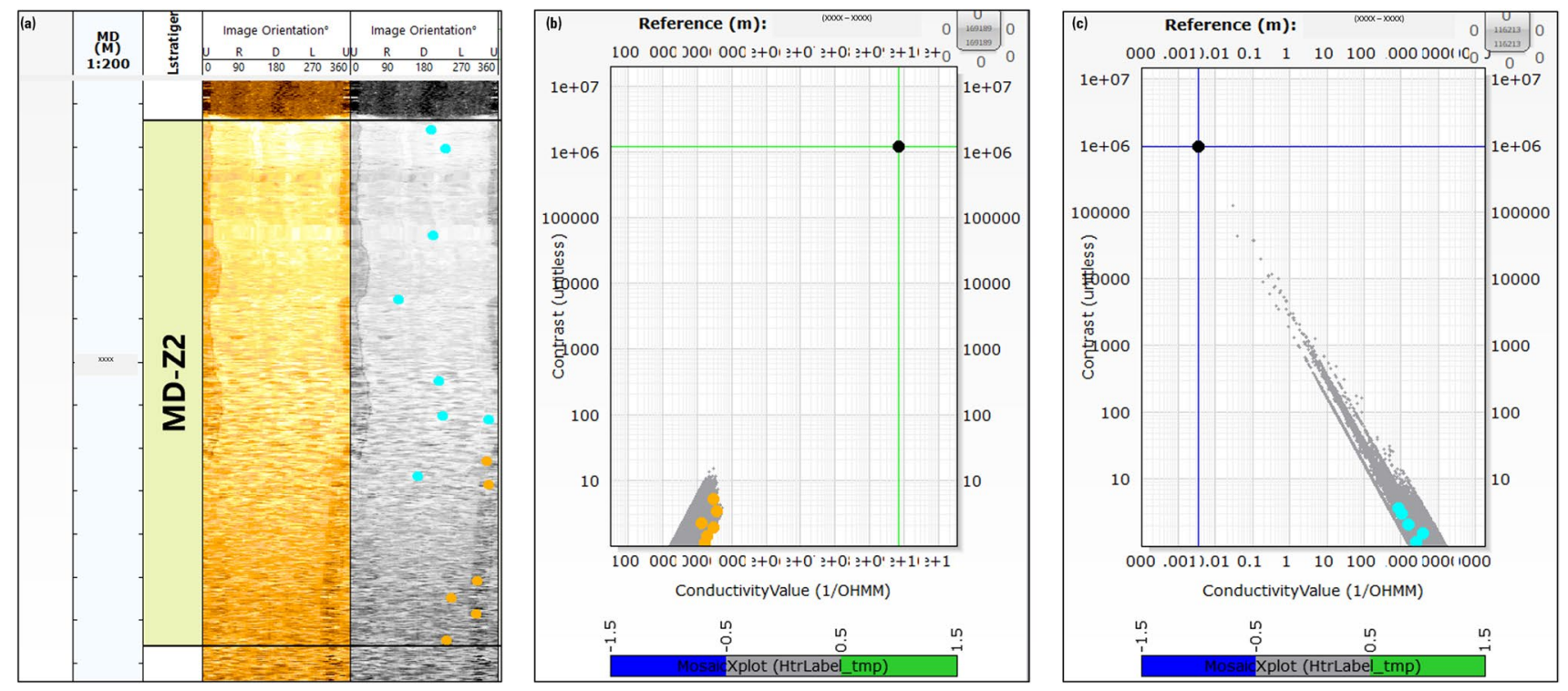

Fig. 14 a Mosaic index image, $\mathbf{b}$ Conductivity and $\mathbf{c}$ Resistivity of the matrix for well \#4 before indexing resistive and conductive area 

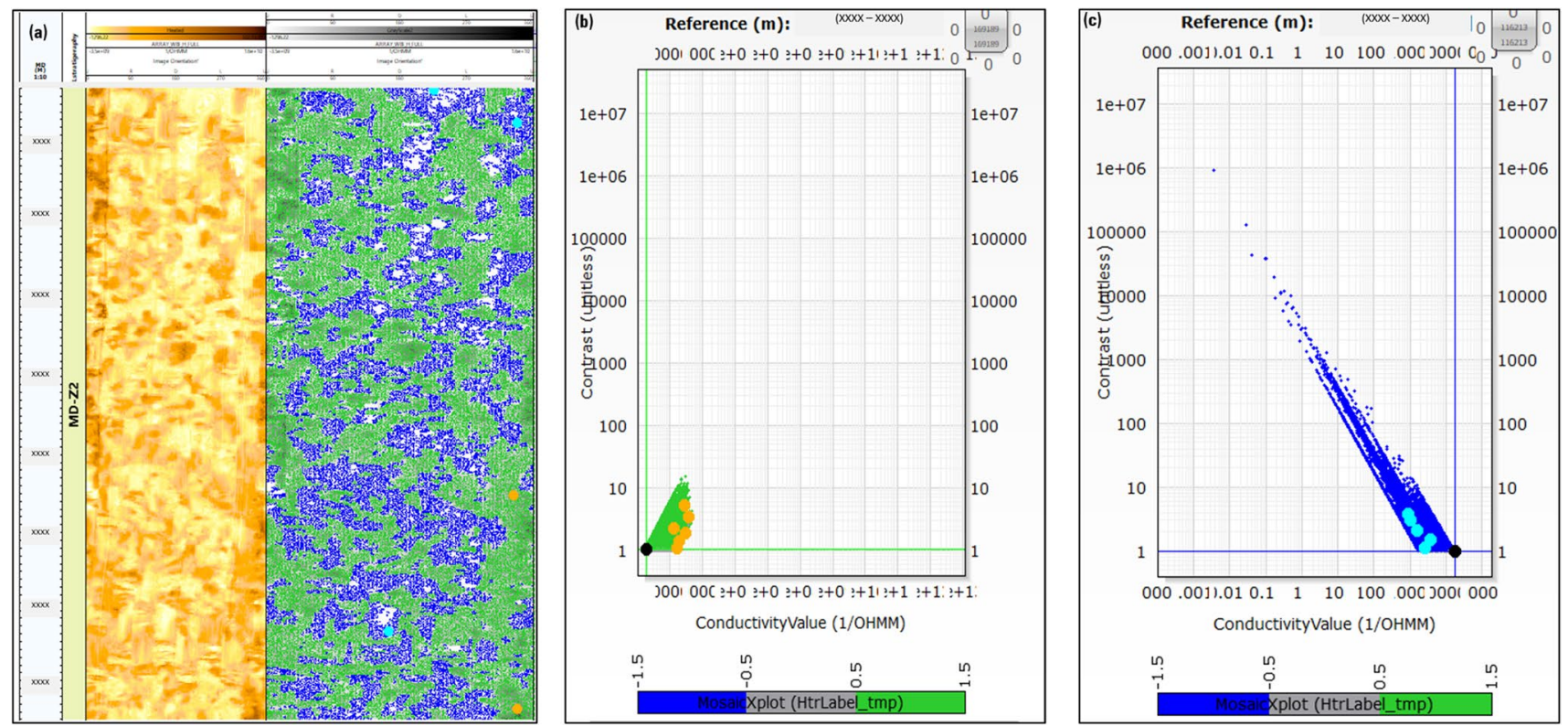

Fig. 15 a Mosaic index image, b Conductivity and $\mathbf{c}$ Resistivity of the matrix for well \#4 after indexing resistive and conductive area

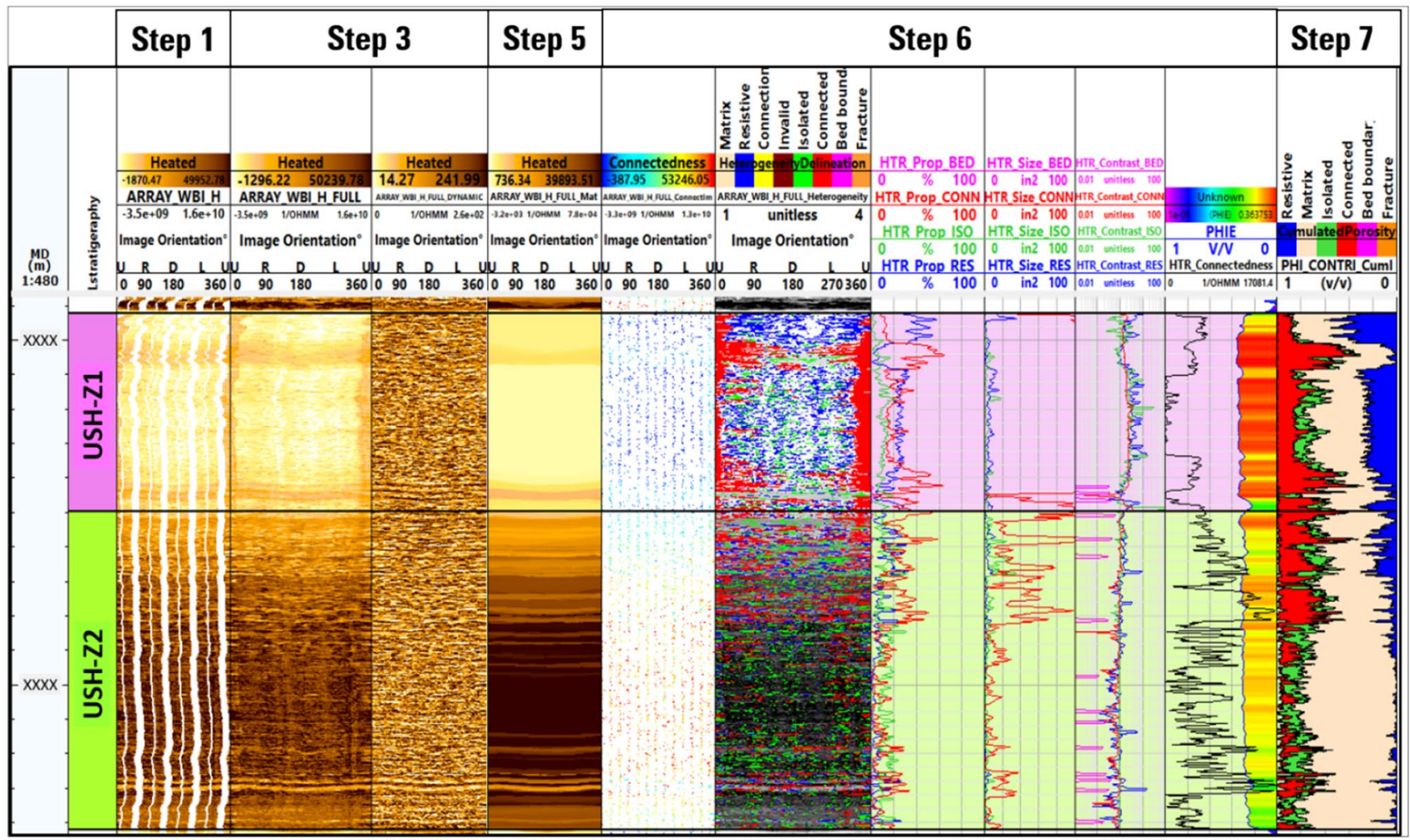

Fig. 16 Heterogeneity analysis with their steps and results for well \#4. Track 3: Static Image log, Track 4: Gap filling the image, Track 5: Mosaic index image, Track 6: Matrix image log, Track 7: Connect- edness image log, Track 8: Heterogeneity image, Track 9: Porosity spectrum value, Track 13: Image porosity distribution 

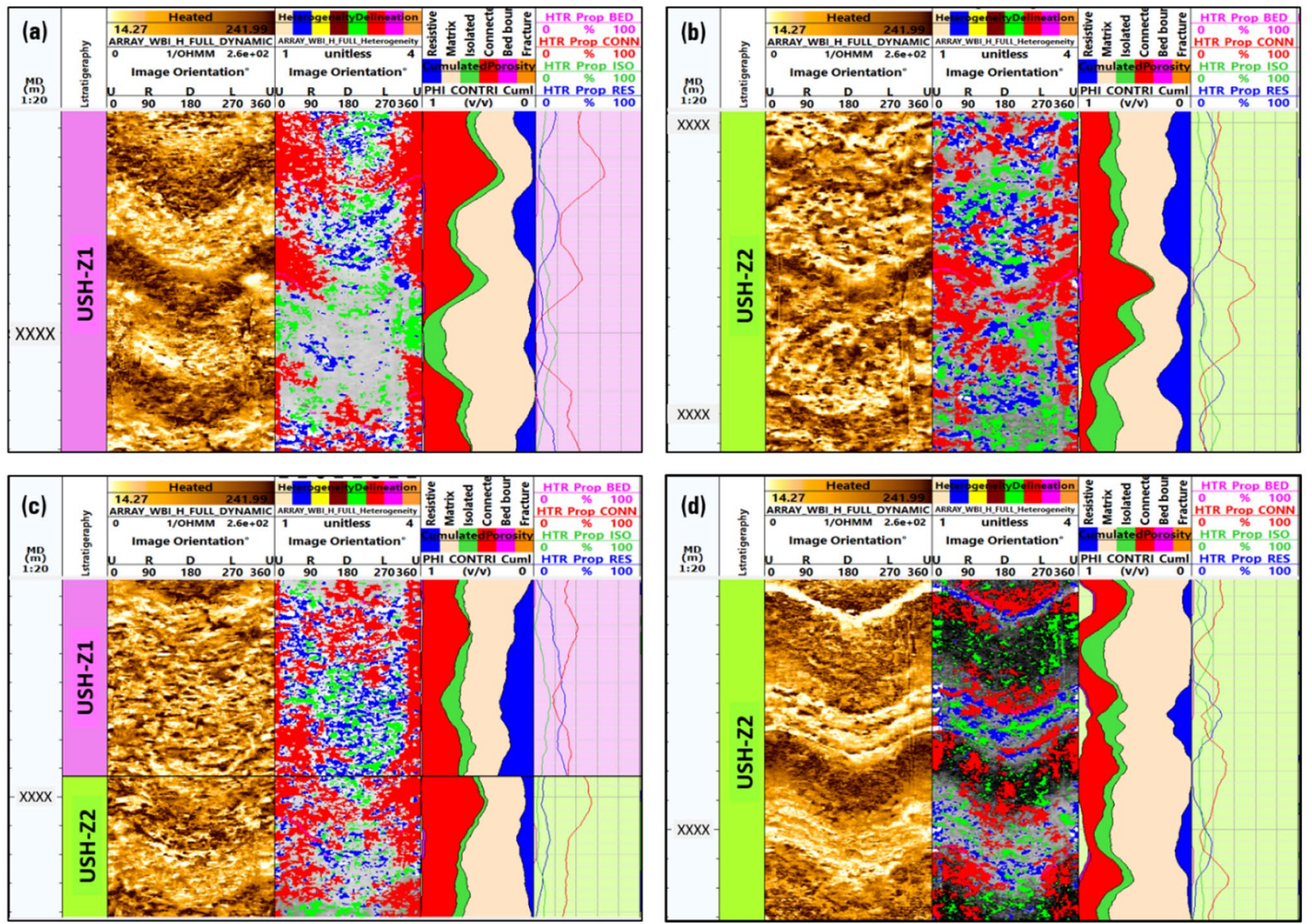

Fig. 17 Heterogeneity results for well \#4 and four distinguished intervals

The PoroTex workflow was determined in this study as a new approach, which was used to categorize various pore types in U. Shuaiba and U. Mauddud Formations by utilizing image $\log$ as an important input. Pore types in mentioned reservoirs such as connected to vuggs, unconnected or isolated vuggs were detected in whole intervals. The contribution of these totally different pore varieties to the overall porousness of the formation is quantified additionally to the geometric info of portrayed pore space. Based on image log data vug porosity is about 5 to 8 percent which is consistent by facies interval from Borehole Image Log data. However, facies evaluation by open hole data was not sensible, by changing on facies (some interval from Packstone to Wackestone) there is no considerable fluctuation on Neutron/Density logs.

Porosity spectrum or porosity distribution study was another important result of this study. By combination of high-resolution dynamic image log with porosity and resistivity log data from open hole logs, porosity distribution was generated as a map which shows all connected and isolated vuggs in both reservoirs appropriately.

The objective of this phase is to distribute the pore types to diversity of heterogeneity types by relating the porosity image and heterogeneity image. The porosity distribution is shown as some histograms of each texture class which are created over vertical windows and are stacked in the same track. The important output can be explained below briefly:

- Vuggy intervals in the U. Mauddud and U. Shuaiba Formation are very obvious. The red intervals show connected vuggs which are seen mostly in USH_Z1 and Z2 Formations in comparison by isolated vuggs as a green interval (Figs. 17, 18).

- Based on porosity spectrum, vug to matrix porosity is domain in reservoir sections.

- 5 Electrical facies were detected by combining of FMI and CMR logs from very good reservoir quality to the tight interval. 


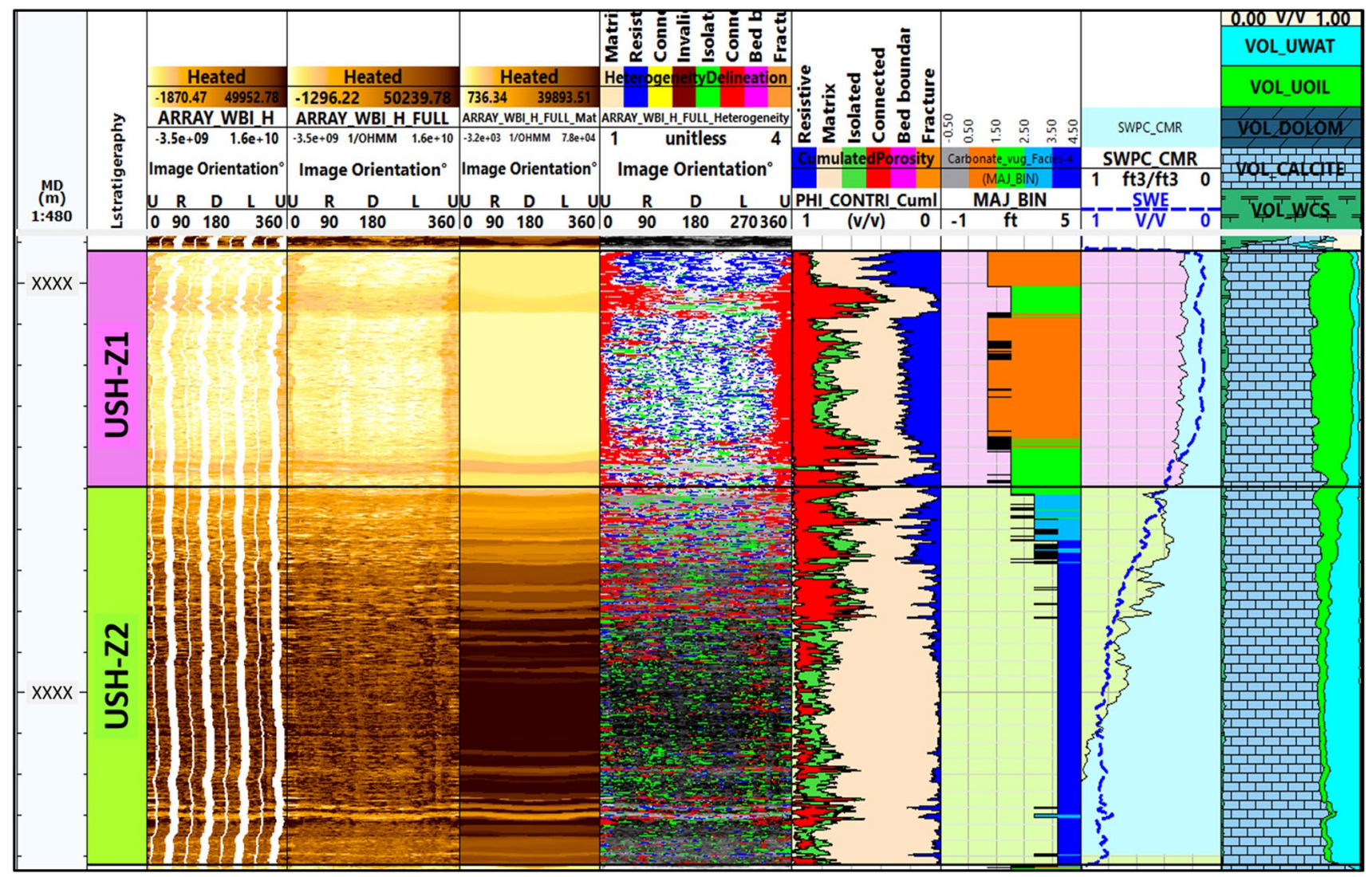

Fig. 18 comparison between porosity distribution from BHI (Track 7) and facies from BHI (Track 8)

- High heterogeneity intervals in the study field indicate the importance of using the advanced log to determine the petrophysical parameters. Presence of wide variety of pore type includes connected and unconnected vuggs; factures shows heterogeneous matrix in upper Mauddud and upper Shuaiba Formations.

Open Access This article is licensed under a Creative Commons Attribution 4.0 International License, which permits use, sharing, adaptation, distribution and reproduction in any medium or format, as long as you give appropriate credit to the original author(s) and the source, provide a link to the Creative Commons licence, and indicate if changes were made. The images or other third party material in this article are included in the article's Creative Commons licence, unless indicated otherwise in a credit line to the material. If material is not included in the article's Creative Commons licence and your intended use is not permitted by statutory regulation or exceeds the permitted use, you will need to obtain permission directly from the copyright holder. To view a copy of this licence, visit http://creativecommons.org/licenses/by/4.0/.

\section{References}

Akbar M et al (2000) A snapshot of carbonate reservoir evaluation. Oilfield Rev 12(4):20-41
Bagci AS, Akbas CY (2007) Permeability estimation using hydraulic flow units in carbonate reservoirs. Paper presented at the rocky mountain oil \& gas technology symposium, Denver, Colorado, U.S.A., 01 Jan 2007

Bijeljic B, Mostaghimi P, Blunt MJ (2013) Insights into non-Fickian solute transport in carbonates. Water Resour Res 49:2714-2728. https://doi.org/10.1002/wrcr.20238

Fitch PJR (2011) Heterogeneity in the petrophysical properties of carbonate reservoirs. University of Leicester

Frazer GW, Wulder MA, Niemann KO (2005) Simulation and quantification of the fine-scale spatial pattern and heterogeneity of forest canopy structure: a lacunarity-based method designed for analysis of continuous canopy heights. For Ecol Manage 214:65-90. https ://doi.org/10.1016/j.foreco.2005.03.056

Frykman P (2001) Spatial variability in petrophysical properties in Upper Maastrichtian chalk outcrops at Stevns Klint, Denmark. Mar Pet Geol 18:1041-1062. https://doi.org/10.1016/S0264 -8172(01)00043-5

Jennings JW Jr, Lucia FJ (2003) Predicting permeability from well $\log$ s in carbonates with a link to geology for interwell permeability mapping. SPE-84942-PA 6:215-225. https://doi. org/10.2118/84942-PA

Lake LW, Jensen JL (1989) A review of heterogeneity measures used in reservoir characterization. Paper SPE 20156 available from SPE, Richardson, Texas

Li H, Reynolds JF (1995) On definition and quantification of heterogeneity. Oikos 73:280-284. https://doi.org/10.2307/3545921

Newberry BM, Grace LM, Stief DO (1996) Analysis of carbonate dual porosity systems from borehole electrical images. Paper presented 
at the permian basin oil and gas recovery conference, Midland, Texas, 01 Jan 1996

Nurmi R, Charara M, Waterhouse M, Park R (1990) Heterogeneities in carbonate reservoirs: detection and analysis using borehole electrical imagery. Geol Soc Lond, Special Publ 48:95-111. https:// doi.org/10.1144/gsl.sp.1990.048.01.09

Potter DK (2007) Magnetic susceptibility as a rapid, non-destructive technique for improved petrophysical parameter prediction. Petrophysics 48(issue 3): 191-201

Pranter MJ, Hirstius CB, Budd DA (2005) Scales of lateral petrophysical heterogeneity in dolomite lithofacies as determined from outcrop analogs: implications for 3-D reservoir modeling. AAPG Bull 89:645-662

Sun H, Vega S, Tao G (2017) Analysis of heterogeneity and permeability anisotropy in carbonate rock samples using digital rock physics. J Petrol Sci Eng 156:419-429. https://doi.org/10.1016/j. petrol.2017.06.002
Tang H, Liu N (2008) Static connectivity and heterogeneity (SCH) analysis and dynamic uncertainty estimation. Paper presented at the IPTC 2008: international petroleum technology conference, 03 December 2008

Westphal H, Eberli GP, Smith LB, Grammer GM, Kislak J (2004) Reservoir characterization of the Mississippian Madison Formation, Wind River basin, Wyoming. AAPG Bulletin 88:405-432. https ://doi.org/10.1306/12020301029

Zhengquan W, Qingcheng W, Yandong Z, Li H (1997) Quantification of spatial heterogeneity in old growth forests of Korean pine. Journal of Forestry Research 8:65-73. https://doi.org/10.1007/ BF02864969

Publisher's Note Springer Nature remains neutral with regard to jurisdictional claims in published maps and institutional affiliations. 